medRxiv preprint doi: https://doi.org/10.1101/2020.06.16.20133116; this version posted June 18, 2020. The copyright holder for this preprint (which was not certified by peer review) is the author/funder, who has granted medRxiv a license to display the preprint in perpetuity.

It is made available under a CC-BY-NC-ND 4.0 International license .

\title{
1 Mental health during the COVID-19 pandemic in two longitudinal UK population cohorts
}

2 Alex S. F. Kwong* 1,2,3, Rebecca, M. Pearson* ${ }^{1,2}$, Mark, J. Adams ${ }^{3}$, Kate Northstone ${ }^{2}$, Kate Tilling

$3 \quad{ }^{1,2}$, Daniel Smith ${ }^{1,2}$, Chloe Fawns-Ritchie ${ }^{4}$, Helen Bould ${ }^{2,5}$, Naomi Warne ${ }^{2}$, Stan Zammit ${ }^{2,6}$, David 4 Gunnell ${ }^{2,7}$, Paul Moran ${ }^{2,7,8}$, Nadia Micali ${ }^{9,10,11}$, Abraham Reichenberg ${ }^{12}$, Matthew Hickman ${ }^{2}$,

5 Dheeraj Rai ${ }^{2,7,8}$, Simon Haworth ${ }^{1,2}$, Archie Campbell ${ }^{13,14}$, Drew Altschul ${ }^{13}$, Robin Flaig ${ }^{13,14}$,

6 Andrew, M. McIntosh ${ }^{3}$, Deborah A. Lawlor ${ }^{1,2,7}$, David Porteous ${ }^{13}$, Nicholas J. Timpson 1,2

$7 \quad{ }^{1}$ MRC Integrative Epidemiology Unit at the University of Bristol, United Kingdom

$8 \quad{ }^{2}$ Population Health Sciences, Bristol Medical School, University of Bristol, UK

$9 \quad{ }^{3}$ Division of Psychiatry, University of Edinburgh, UK

${ }^{4}$ Department of Psychology, University of Edinburgh, UK

${ }^{5}$ Gloucestershire Health and Care NHS Foundation Trust, Gloucester, UK

${ }^{6}$ MRC Centre for Neuropsychiatric Genetics and Genomics, Division of Psychological Medicine and Clinical Neurosciences, Cardiff University, Cardiff, UK

${ }^{7}$ National Institute of Health Research (NIHR) Biomedical Research Centre, University of Bristol,

Bristol, United Kingdom

${ }^{8}$ Avon and Wiltshire Mental Health Partnership National Health Service (NHS) Trust, Bristol, United

Kingdom

${ }^{9}$ Great Ormond Street Institute of Child Health, University College London, London, UK

${ }^{10}$ Department of Psychiatry, Faculty of Medicine, University of Geneva, Geneva, Switzerland.

${ }^{11}$ Department of Paediatrics Gynaecology and Obstetrics, Faculty of Medicine, University of Geneva,

Geneva, Switzerland

${ }^{12}$ Department of Psychiatry, Icahn School of Medicine at Mount Sinai, New York, NY, USA

${ }^{13}$ Centre for Genomic and Experimental Medicine, Institute of Genetics \& Molecular Medicine,

${ }^{14}$ Usher Institute for Population Health Sciences and Informatics, University of Edinburgh, Edinburgh,

*Contributed equally to this work / Contributed equally to this work

Corresponding Author: Alex S. F. Kwong, Population Health Sciences, Bristol Medical School,

E: Alex.Kwong@Bristol.ac.uk

Word count: 3917 (excluding abstract, tables, figures and references)

Keywords: COVID-19; pandemic; mental health; ALSPAC; Generation Scotland; depression; anxiety; wellbeing; longitudinal 
medRxiv preprint doi: https://doi.org/10.1101/2020.06.16.20133116; this version posted June 18, 2020. The copyright holder for this preprint (which was not certified by peer review) is the author/funder, who has granted medRxiv a license to display the preprint in perpetuity.

It is made available under a CC-BY-NC-ND 4.0 International license.

\section{Summary}

Background: The impact of COVID-19 on mental health is unclear. Evidence from longitudinal studies with pre pandemic data are needed to address (1) how mental health has changed from prepandemic levels to during the COVID-19 pandemic and (2), whether there are groups at greater risk of poorer mental health during the pandemic?

Methods: We used data from COVID-19 surveys (completed through April/May 2020), nested within two large longitudinal population cohorts with harmonised measures of mental health: two generations of the Avon Longitudinal Study of Parents and Children (ALPSAC): the index generation ALSPAC-G1 ( $\mathrm{n}=2850$, mean age 28) and the parent's generation ALSPAC-G0 $(\mathrm{n}=3720$, mean age = 59) and Generation Scotland: Scottish Family Health Study (GS, $(n=4233$, mean age $=59)$, both with validated pre-pandemic measures of mental health and baseline factors. To answer question 1 , we used ALSPAC-G1, which has identical mental health measures before and during the pandemic. Question 2 was addressed using both studies, using pre-pandemic and COVID-19 specific factors to explore associations with depression and anxiety in COVID-19.

Findings: In ALSPAC-G1 there was evidence that anxiety and lower wellbeing, but not depression, had increased in COVID-19 from pre-pandemic assessments. The percentage of individuals with probable anxiety disorder was almost double during COVID-19: 24\% (95\% CI 23\%, 26\%) compared to pre-pandemic levels $(13 \%, 95 \%$ CI 12\%, 14\%), with clinically relevant effect sizes. In both ALSPAC and GS, depression and anxiety were greater in younger populations, women, those with pre-existing mental and physical health conditions, those living alone and in socio-economic adversity. We did not detect evidence for elevated risk in key workers or health care workers.

Interpretation: These results suggest increases in anxiety and lower wellbeing that may be related to the COVID-19 pandemic and/or its management, particularly in young people. This research highlights that specific groups may be disproportionally at risk of elevated levels of depression and anxiety during COVID-19 and supports recent calls for increasing funds for mental health services.

Funding: The UK Medical Research Council (MRC), the Wellcome Trust and University of Bristol. 


\section{Introduction}

The coronavirus disease 2019 (COVID-19) pandemic has resulted in radical changes to societies globally. As the number of infected cases and deaths increased, many countries adopted public health measures including lockdown, social distancing and self-isolation. While such measures may be important for reducing transmission, they may also have a profound effect on mental health, [1-3] However, the extent to which mental health is affected by COVID-19 and its management, and who is at greatest risk, is unknown. Longitudinal studies with pre-pandemic data are vital for addressing this.

Although not directly comparable to COVID-19, evidence from previous viral outbreaks provide relevant information. The Severe Acute Respiratory Syndrome epidemic (SARS) resulted in public health mitigation measures in some countries and was associated with an increase (from pre-pandemic levels) in anxiety, depression, suicide and post-traumatic stress disorder during and beyond the conclusion of the outbreak for survivors of the virus, [4-6] and the unexposed public. [7, 8] Compared to SARS, the COVID-19 pandemic is greater in scale, resulting in more infections and deaths as well as more extreme mitigation methods. The consequences for mental health resulting from the COVID19 pandemic could therefore be substantial. [1, 9] Unlike previous outbreaks, COVID-19 is widespread meaning the impact on global economy and health could be unprecedented.

Several rapid cross-sectional surveys during the COVID-19 pandemic have suggested a higher prevalence of anxiety, depression, $[10,11]$ and low wellbeing compared to historical estimates. [12, 13] However, these studies lack pre-pandemic information in the same people, reporting symptoms during and before the pandemic. This precludes accurate assessment of changes in mental health. Furthermore, selection (due to mental health influencing who respond to surveys) and reporting bias (those who perceive depression and anxiety as higher or are more likely to report symptoms when they feel there is a 'valid' reason) could threaten the validity of results from cross-sectional surveys. [14] There is a need for data from longitudinal designs with well-characterized sampling frames and pre-pandemic data. Such studies can more accurately identify changing patterns of mental health and identify risk groups, informing development of interventions for those at heightened risk and aiding policy decisions regarding the immediate management of COVID-19, including plans for easing restrictions, as well as for the longer-term care for groups whose mental health may be particularly affected. [1,9]

The COVID-19 pandemic is likely to exacerbate existing social and psychological inequalities. [15] Previous studies have identified several groups who may be at greater risk of poorer mental health during COVID-19, including younger people, women, healthcare workers and those with poorer financial or living circumstances. [10,11, 13, 16] Parents with school-aged children, individuals at risk of physical and emotional abuse and those at greater physical risk of COVID-19 (older age, and 
medRxiv preprint doi: https://doi.org/10.1101/2020.06.16.20133116; this version posted June 18, 2020. The copyright holder for this preprint

(which was not certified by peer review) is the author/funder, who has granted medRxiv a license to display the preprint in perpetuity.

It is made available under a CC-BY-NC-ND 4.0 International license.

95 those with chronic conditions such as, asthma, obesity, diabetes) may also be at heightened risk of

96 poorer mental health.

97 We used data from two large longitudinal cohort studies, both with rich pre-pandemic measures of 98 mental health, to address (1) how has mental health changed from pre-pandemic levels to the COVID-

9919 pandemic and (2) are there groups at greater risk of poorer mental health during the pandemic? The

100 first of these is important for exploring the impact of COVID-19 and its management on mental health

101 and potential increases in poor mental health long-term. The second is important for targeting of

102 mental health care needs now and during any subsequent waves and for identifying groups who might

103 benefit from long-term monitoring after the pandemic. 
We selected two comparable cohort studies to allow replication in different regions of the UK, but with similar timings of mental health measures before and during the COVID-19 pandemic.

The Avon Longitudinal Study of Parents and Children (ALSPAC) is an ongoing longitudinal population-based study that recruited pregnant women residing in Avon in the south-west of England with expected delivery dates between $1^{\text {st }}$ April 1991 and $31^{\text {st }}$ December 1992. [17, 18] The cohort consists of 13,761 mothers and their partners (hereafter referred to as ALSPAC-G0), and their 14,901 children (ALSPAC-G1). [19] The study website contains details of all data available through a fully searchable data dictionary (http://www.bristol.ac.uk/alspac/researchers/our-data/). Ethical approval for the study was obtained from the ALSPAC Ethics and Law Committee and the Local Research Ethics Committees.

Generation Scotland: Scottish Family Health Study (GS) is a family longitudinal study of 24,084 individuals recruited across Scotland between 2006 and 2011.[20] Participants were recruited into the study if they were aged 18 or over. Participants of GS have been followed up longitudinally, [21] and further details can be found on the study website (http://www.generationscotland.org). Ethical approval for the study was approved by NHS Tayside Committee on Medical Research Ethics (reference 05/S1401/89).

This study uses data from 3720 ALSPAC-G0 and 2973 ALSPAC-G1 who completed an online questionnaire about the impact and consequences of the COVID-19 pandemic between $9^{\text {th }}$ April and $14^{\text {th }}$ May 2020 (see, appendix figure 1 and figure 2) [22]. In GS, data were from 4,233 individuals who completed a similar online COVID-19 questionnaire between 17 th $^{\text {April }}$ and 17 $7^{\text {th }}$ May 2020 (see, appendix figure 3). Lockdown was announced in the UK on the $24^{\text {th }}$ March.

\section{COVID-19 pandemic measures of mental health}

128 The measures used in the COVID-19 survey examine symptoms in the preceding 2 weeks, thus represent mental health in the immediate period following lockdown. Depressive symptoms in ALSPAC were measured using the Short Mood and Feelings Questionnaire (SMFQ), [23] a 13-item instrument examining depressive mood. Scores range between 0-26 with higher scores indicting higher depressive symptoms. In GS, depressive symptoms were measured using the Patient Health Questionnaire (PHQ-9), [24] a 9-item instrument which monitors depressive symptoms. Scores range between 0-27 with higher scores indicating worse depressive symptoms. Anxiety symptoms in ALSPAC and GS was measured using the same instrument, the Generalised Anxiety Disorder Assessment (GAD-7), [25] a 7-item instrument which measures the presence of generalised anxiety 
disorder symptoms. Scores range between 0-21 with higher scores indicting higher anxiety symptoms. Mental wellbeing in ALSPAC and GS was also measured using the same instrument, the Short Warwick-Edinburgh Mental Wellbeing Scale (SWEMWBS), [26] a 7-item instrument which measures positive mental wellbeing. Scores range between 7-35, with higher scores indicating better mental wellbeing. These measures have recommended cut-offs for examining the proportion of individuals with probable depression ( $\geq 11$ on SMFQ and $\geq 10$ on PHQ-9), generalised anxiety disorder ( $\geq 10$ on GAD-7) and poor mental wellbeing ( $\leq 17$ on SWEMWBS), with good sensitivity and specificity for identifying clinical disorder using validated interviews and instruments and widely used in primary care and clinical trials (see appendix methods). Herein we refer to depressive symptoms as depression and anxiety symptoms as anxiety.

\section{Baseline (pre-pandemic) measures of mental health and factors}

Baseline depression and anxiety were assessed in ALSPAC and GS prior to the COVID-19 pandemic. In ALSPAC-G1, baseline mental wellbeing was also assessed. These measures are described in Table 1 , alongside information on the baseline factors that may predict poorer mental health in COVID-19. We refer to these as factors to make it clear that we are not assuming they are causal but could be useful for identifying vulnerable groups. The factors we explored included demographic and social information such as sex, age, educational background, financial circumstances, deprivation status, victimisation and being a parent with school-aged children. Additional factors included pre-existing mental health conditions, substance misuse, genetic risk for depression, cognitive styles, personality traits and difficulties accessing mental health information. Due to differences in data collection, several factors are only assessed in either ALSPAC or GS. We also examined associations with several COVID-19 specific factors that may be valuable predictors of adverse mental health, including obesity, asthma, infection status, isolation status, living alone, access to a garden, healthcare worker and key worker status. Detailed information regarding the descriptions and timing of these measures including availability and how measures were harmonised, are given in the appendix method section.

\section{Statistical analysis}

Analysis was conducted in StataSE (version 15). Initially, we described the prevalence of mental health outcomes during the COVID-19 pandemic in all cohorts. To answer our first research question, we used ALSPAC-G1 to examine how mental health changed from baseline (pre-pandemic) to COVID-19 levels. This analysis was only possible in ALSPAC-G1 who had identical mental health measures at baseline and during COVID-19.

To answer our second research question, we examined associations between factors (both baseline measures and those specific to and measured during the pandemic) and COVID-19 depression and 
anxiety. Analysis was conducted separately for all cohorts, adjusting for sex, age and the date they completed the COVID-19 questionnaire (to account for heterogeneity in response times). In ALSPAC-G0 and GS, we used alternative measures capturing the same construct to account for preexisting depression and anxiety (the EPDS in ALSPAC-G and the GHQ-28 in GS). Wellbeing was not assessed at baseline in ALSPAC-G1 or GS, therefore we restrict this analysis to depression and anxiety only. The results for question two can be interpreted as identifying factors associated with depression and anxiety, that are not driven by past symptoms of either disorder (as they are adjusted for in the model). Continuous COVID-19 and baseline depression and anxiety were standardised to create $\mathrm{Z}$ scores allowing comparison of effect sizes across outcomes and cohorts.

\section{Missing data}

Our eligible samples were defined as those who completed at least one mental health measure during the COVID-19 surveys: ALSPAC-G0 n= 3579, ALSPAC-G1 $n=2872$ and GS $n=4208$ (appendix figures 1-3, appendix table 1). We imputed incomplete baseline depression, anxiety and factors using earlier or concurrent information up to the eligible samples, using multiple imputation by chained equations to generate 50 imputed datasets. [27] Full information on the proportion of missing baseline data in each cohort are given in the appendix table $2-4$, the majority (>80\%) of participants had more than $50 \%$ of complete baseline data (i.e., all factors and baseline mental health) with less than $1 \%$ only having information on only 1 or 2 baseline variables. Analyses on multiple imputed datasets uses rich pre-pandemic data available to plausibly meet the assumption that data are missing at random, i.e., conditional on observed information. Whereas, complete case analyses assume that missingness is not related to the outcome conditional on the exposure and any covariables. Given that we have demonstrated that the missing baseline data was associated with lower education and sex (appendix table 1) it is likely that the complete case sample is biased and thus we primarily present imputed estimates which also increase power. Details regarding imputation are fully described in the appendix.

Sensitivity analyses

In sensitivity analysis, we also examined depression and anxiety using the 'proportion-abovethreshold' in logistic regressions rather than continuous scores as outcomes, analysed varying ages for baseline measures and estimated 'counterfactual' trajectories for the mental health measures to highlight differences in the observed compared to predicted trajectories.

\section{Role of the funding source}

The funders of the study had no role in the study design, data collection, data analysis, data interpretation, or writing of this manuscript. The corresponding author had full access to the data in the study and had final responsibility for the decision to submit for publication. 
medRxiv preprint doi: https://doi.org/10.1101/2020.06.16.20133116; this version posted June 18, 2020. The copyright holder for this preprint (which was not certified by peer review) is the author/funder, who has granted medRxiv a license to display the preprint in perpetuity.

It is made available under a CC-BY-NC-ND 4.0 International license

205

206

207

208

209

210

211

212

213

214

215

216

217

218

219

220

221

222

223

224

225

226

227

228

229

230

231

232

233

234

235

236

\section{Results}

Data on COVID-19 mental health outcomes in ALSPAC-G0 were available for 3579 people (mean age: 58.67 years, SD: 4.82), for ALSPAC-G1, 2872 people (mean age: 27.61 years, SD: 0.54 ) and GS 4208 people (mean age: 59.24 years, SD: 12.03), see appendix figures 1-3, appendix table 1.

\section{Prevalence of mental health outcomes during COVID-19}

The prevalence of probable depression decreased with age in ALSPAC and GS. Similar results were observed for probable anxiety and low wellbeing (Figure 1).

\section{Change in mental health in ALSPAC-G1}

The percentage of individuals with probable depression was lower, $18.14 \%(16.76,19.61)$, in COVID, compared to $24.35 \%(23.04,25.70)$ at the most recent baseline. The percentage of people with probable anxiety disorder was almost double during COVID-19:24\% (95\% CI 23\%,26\%) compared to pre-pandemic levels $(13 \%, 95 \%$ CI $12 \%, 14 \%)$ and for lower wellbeing :13, (95\% CI 12 to $14 \% \%$ ) compared to $8 \%$ (95\% CI 7 to $9 \%$ ) (Figure 2, appendix table 5 and 6). When examining continuous measures of mental health, there was a mean difference in SMFQ score of -0.60 (95\% CI: $-0.84,-0.37), 1.36$ (95\% CI: 1.10, 1.61) for GAD-7 and 2.45 (95\% CI 2.25 to 2.65) for SWEMWBS, when comparing the most recent baseline to COVID-19. To give a summary of magnitude, these estimates represent a $0.11,0.26$ and 0.51 standardised effect difference respectively (appendix table 7). Item level differences for each measure are shown in figure 3.

Factors related to depression and anxiety during COVID-19

Table 2 and figures 4 and 5 show the associations between baseline and COVID-19 specific factors and depression and anxiety, with adjustment for baseline depression and anxiety symptoms (measured on a continuous scale in standard deviation units for ease of comparison between cohorts and outcomes).

A reported or suspected COVID-19 infection was associated with higher depression and anxiety in ALSPAC-G0, but only higher depression in GS with no associations observed in ALSPAC-G1.

Living alone during the pandemic was associated with higher depression, but not with higher anxiety in ALSPAC and GS. No access to a garden was associated with higher depression in all cohorts and greater anxiety in GS. ALSPAC-G0 and ALSPAC-G1 participants who reported that they had selfisolated had higher depression and anxiety, but it was not possible to test this in GS. Key workers (of any kind) and health care workers were not associated with higher depression or anxiety. There was an association between being a key worker and having lower depression in ALSPAC-G1, but this was not replicated in ALSPAC-G1 or GS. 
medRxiv preprint doi: https://doi.org/10.1101/2020.06.16.20133116; this version posted June 18, 2020. The copyright holder for this preprint (which was not certified by peer review) is the author/funder, who has granted medRxiv a license to display the preprint in perpetuity.

It is made available under a CC-BY-NC-ND 4.0 International license.

237 For pre-pandemic factors, focusing on replicated results (those showing consistent associations in at

238 least two cohorts), we found evidence for higher depression and anxiety in women, those with

239 financial problems, lower educational backgrounds, lower income, living in a more deprived area,

240 those with obesity. A positive association of being a parent of a young child with higher anxiety in

241 ALSPAC-G1 did not replicate in GS and was not associated with depression in either cohort.

242 Reporting an emotionally abusive partner was only available in ALSPAC-G0 but was positively

243 associated with both greater depression and anxiety. Asthma had positive associations with higher

244 anxiety in ALSPAC-G1 and GS but was not associated with depression in both cohorts.

245 There were strong and replicated associations between several pre-existing mental health problems

246 and higher depression and anxiety, including a history of major depression disorder, psychosis-like

247 symptoms, negative cognition, neuroticism, and a history of self-harm. The depression polygenic risk

248 score was also positively associated with depression and anxiety in ALSPAC-G0 and GS (though not

249 in ALSPAC-G1).

250 Depression and anxiety were higher in ALSPAC-G1 in those who reported generalised anxiety

251 disorder, OCD traits, disordered eating, autistic traits, and difficulty accessing mental health services,

252 but these outcomes were not available in ALSPAC-G1 or GS and so could not be replicated.

253 Personality disorder traits were associated only with higher anxiety in G1 but both anxiety and

254 depression ALSPAC-G0. A history of alcohol abuse was associated with increased depression in

255 ALSAPC-G1 and anxiety in both ALSAPC-G0 and ALSPAC-G1, but not replicated in GS. By

256 contrast smoking was associated with increased depression and anxiety in both ALSPAC-G0 and GS

257 but not ALSPAC-G1.

258 Results were similar using complete case analysis (appendix table 8), adjusting for educational

259 background with imputation (appendix table 9), using different timings of baseline depression and

260 anxiety (appendix tables 10 and 11) and examining binary outcomes (appendix table 12). 


\section{Discussion}

We report a population-based longitudinal study to track changes in depression and anxiety from before to during the COVID-19 pandemic, providing potentially important new information for policy planning. Although we found no clear evidence that depression has changed during COVID-19 from pre-pandemic waves in ALSPAC-G1, there was strong observational evidence that anxiety and lower wellbeing were higher during COVID-19 compared to pre-pandemic levels. Approximately twice as many young adults experienced probable anxiety disorder and low wellbeing during the pandemic compared to previous waves. The mean rises of $0.26 \mathrm{SD}$ in GAD-7 scores and $0.51 \mathrm{SD}$ in SWEMWBS represent effect sizes that are clinically important and are seen in those following treatment (in the opposite direction). [28, 29] While mental health is dynamic and changes over time, evidence suggests that mood disorders tend to stabilise throughout adulthood, so the rise in anxiety and reduction in wellbeing in ALSPAC-G1 goes against what we would expect in the absence of COVID-19. [30] Our trajectory analyses (see appendix figure 4) suggested that higher anxiety and lower wellbeing deviated from expected levels, but that depression was in line with expectations in comparison to previous waves.

The uncertainty and sudden change to everyday life, as well as concerns over health, may explain why anxiety, rather than depression, has initially risen. The apparent rise in younger ages may reflect the impact of mitigation measures (i.e., lockdown and social distancing) rather than a risk of COVID-19 infection (which may be higher in older populations). Furthermore, depression usually relates to feelings of loss, whilst anxiety relates to threat, as the majority of participants may not yet have lost anything (e.g., death of loved one, loss of job) this may also explain why depression has currently remained stable. There is also evidence that anxiety changes more rapidly than depression following treatment. [28]. What separates this pandemic from historical outbreaks, is the global impact. This, alongside the community spirit, may have been protective against the self-blame and guilt intrinsic to depression. [31] Indeed, depression items that were lower in the pandemic, as compared to previous waves, related to feelings of self-blame. As social inequalities become apparent and threat of loss becomes actual loss, this may change. The current survey was in UK spring, whereas previous ALSPAC-G1 waves were predominantly completed in winter. Seasonal trends suggest that depression and anxiety scores are approximately 1-2 points (0.1 SD) lower and $5 \%$ less of individuals are above thresholds in spring than winter, [32] which may explain lower depression scores.

Irrespective of the overall change in depression and anxiety in each cohort, several sociodemographic, psychological, physical and COVID-19 factors were associated with greater depression and anxiety during COVID-19. A reported or suspected COVID-19 infection was a factor for higher depression and anxiety in ALSPAC-G0 and GS, possibly reflecting the high perceived risk to physical health in older ages. This supports previous research, [2] but must be interpreted with caution because COVID- 
19 status here largely includes participants' perception that they have COVID-19. Therefore, it maybe that those with pre-existing depression and anxiety are more likely to perceive that their symptoms are COVID-19 rather than other conditions. There was consistent evidence in participants from ALSPAC and GS that health risk groups linked to COVID-19, such as those with obesity and to some extent asthma, had higher depression and anxiety during COVID-19, potentially reflecting concerns regarding perceived risk of infection or the impact of more stringent social distancing. There was no evidence that key workers or health workers were at greater risk of depression or anxiety, suggesting these groups are not yet experiencing difficulties. This may reflect the heterogenous group of occupations included in this group, but whilst we observed no initial change in these groups, as the situation continues, frontline health care workers may become at risk of PTSD.

Those reporting self-isolation were at higher risk of both anxiety and depression but living alone was consistently associated with greater depression only. The manifestation of depression rather than anxiety for those living alone may relate to loneliness which is amplified with physical contact restricted to within households, again reflecting depression being related to absence and loss rather than threat. Whereas, self-isolation (which in this context is related to having symptoms) may be linked to anxiety through associated threat of the virus. Parents of young children were more anxious in ALSPAC, which may reflect stress related to the sudden change in childcare provision. Financial problems, lower income and deprivation were associated with greater risk of depression and anxiety in ALSPAC-G0 and GS. Financial problems, but not lower income, was also associated with higher depression and anxiety in ALSPAC-G1. Whilst these cohorts may have different populations, replication of financial concerns highlights the potential importance of global policies to mitigate the sudden social-economic impact and ensure emergency financial measures are accessible. [16]

As expected, individuals with a history of poorer mental health across multiple domains were at greater risk of higher depressive and anxiety during COVID-19, supporting concerns raised at the beginning of this pandemic. [1,33,34] Personality traits such as neuroticism and negative thinking patterns are strong factors for higher depression and anxiety during COVID-19 and are modifiable with interventions which could benefit those at risk now or in future outbreaks, even if delivered remotely. [35] ALSPAC-G0 and GS participants with genetic risk for depression were associated with poorer mental health, yet these effects were much weaker in ALSPAC-G1.

There are several limitations to this work. Firstly, as the pandemic is a universal exposure, it is difficult to attribute factors to the impact of the COVID-19 pandemic specifically, with many factors likely to show an association with later depression and anxiety at any time. [31] However, using longitudinal data and methods, we were able to demonstrate that anxiety and lower wellbeing were worse during COVID-19 than expected, given the comparison between baseline and pandemic assessments, so it is unlikely these effects are not related to COVID-19. Secondly, there were 
medRxiv preprint doi: https://doi.org/10.1101/2020.06.16.20133116; this version posted June 18, 2020. The copyright holder for this preprint (which was not certified by peer review) is the author/funder, who has granted medRxiv a license to display the preprint in perpetuity.

It is made available under a CC-BY-NC-ND 4.0 International license.

331

332

333

334

335

336

337

338

339

340

341

342

343

344

345

346

347

348

349

350

351

352

353

354

355

heterogeneous measurements of mental health in COVID-19 specific surveys and baseline, as well as differences in the length of follow up across cohorts. This poses a challenge in inferring strong conclusions on change and specificity of findings to generations or cohorts. However, several sensitivity analyses in both cohorts and exploring different baselines reached similar conclusions. Thirdly, we were only able to assess change over the pandemic in ALSPAC-G1. Therefore, our inferences may only be relevant to young adult populations. However, given the replication between younger ages and higher rates of depression and anxiety, it is likely these effects will be observed in other studies. Fourthly, although we were able to use existing data such as educational background to predict baseline missingness and use such variables in imputation models, we did not impute further than the sample with complete COVID-19 survey data, given that data was unique. Thus, there may be issues with generalisability as respondents were more likely to be female and from higher educational backgrounds than previous ALSPAC and GS surveys. Furthermore, the meaning and interpretation of depression, anxiety and wellbeing may vary during pandemics, for example, some level of tension and fear may be adaptive and appropriate. However, our item level analysis revealed that all anxiety and mental wellbeing items were worse during COVID-19, implying a global decrease in these aspects of mood, not just for specific components. Finally, we compared multiple factors and therefore some statistical associations may have occurred as a result of chance. However, for most factors, there was evidence for replication of findings across multiple cohorts, suggesting that 'chance' findings are less likely.

Future work is needed to understand the mechanisms and complex interplay between baseline and COVID-19 specific factors and mental health during the COVID-19 pandemic. Future research should also consider how changes in anxiety might influence public behaviour through contact patterns and compliance with policies. Depression and anxiety, along with associated impairment should continue to be carefully monitored to forecast the long-term impact of this crisis. This can help ensure that future policies consider optimal preservation of both physical and mental health. 
medRxiv preprint doi: https://doi.org/10.1101/2020.06.16.20133116; this version posted June 18, 2020. The copyright holder for this preprint (which was not certified by peer review) is the author/funder, who has granted medRxiv a license to display the preprint in perpetuity.

It is made available under a CC-BY-NC-ND 4.0 International license

\section{Contributors}

ASFK, RMP, MJA, KN, KT, AMM, DAL, DP and NJT contributed to the conception and design of the study. ASFK, RMP, MJA, KN, AC, SH, CFR, DA, RF, DS, DP and NJT contributed to the organisation of the conduct of the study. ASFK carried out the study (including acquisition of data). ASFK and MJA analysed the data. ASFK and RMP drafted the initial output. All authors contributed to the interpretation of data. All authors have read and approved the final version of the manuscript. ASFK will serve as guarantor for the contents of the paper.

\section{Declaration of interests}

We declare no competing interests.

\section{Data availability}

ALSPAC data is available to researchers through an online proposal system. Information regarding access can be found on the ALSPAC website (http://www.bristol.ac.uk/medialibrary/sites/alspac/documents/researchers/data-access/ALSPAC_Access_Policy.pdf).

GS:SFHS data is available to researchers on application to the Generation Scotland Access Committee (access@generationscotland.org). The managed access process ensures that approval is granted only to research which comes under the terms of participant consent.

\section{Acknowledgments}

The UK Medical Research Council and Wellcome (Grant Ref: 217065/Z/19/Z) and the University of Bristol provide core support for ALSPAC. A comprehensive list of grants funding is available on the ALSPAC website (http://www.bristol.ac.uk/alspac/external/documents/grant-acknowledgements.pdf). We are extremely grateful to all the families who took part in this study, the midwives for their help in recruiting them, and the whole ALSPAC team, which includes interviewers, computer and laboratory technicians, clerical workers, research scientists, volunteers, managers, receptionists and nurses. Part of this data was collected using REDCap, see the REDCap website for details https://projectredcap.org/resources/citations/). ASFK, RMP, KT, DS, SH, DAL, NJT work in or are affiliated to the MRC Integrative Epidemiology Unit which is funded by the University of Bristol and UK Medical Research Council (MC_UU_00011/3 and MC_UU_00011/6). European Research Council under the European Union's Seventh Framework Programme, and grants 758813, MHINT and 669545 from the European Research Council Grant Agreements. This work was supported by Wellcome through the Wellcome Longitudinal Population Studies COVID-19 Secretariat and Steering Group (UK LPS COVID co-ordination, Grant Ref: 221574/Z/20/Z). This work was also supported by the NIHR Biomedical Research Centre at University Hospitals Bristol NHS Foundation Trust and the University of Bristol. Generation Scotland received core support from the Chief 
medRxiv preprint doi: https://doi.org/10.1101/2020.06.16.20133116; this version posted June 18, 2020. The copyright holder for this preprint (which was not certified by peer review) is the author/funder, who has granted medRxiv a license to display the preprint in perpetuity.

It is made available under a CC-BY-NC-ND 4.0 International license .

389 Scientist Office of the Scottish Government Health Directorates [CZD/16/6] and the Scottish Funding

390 Council [HR03006], and is currently supported by the Wellcome Trust [216767/Z/19/Z]. Genotyping

391 of the GS:SFHS samples was carried out by the Genetics Core Laboratory at the Wellcome Trust

392 Clinical Research Facility, University of Edinburgh, Scotland, funded by the MRC and Wellcome

393 Trust [104036/Z/14/Z]. This work has made use of the resources provided by the Edinburgh Compute

394 and Data Facility (ECDF) (http://www.ecdf.ed.ac.uk/). NJT is a Wellcome Trust Investigator

395 (202802/Z/16/Z), is the PI of the Avon Longitudinal Study of Parents and Children (MRC \& WT

$396217065 / Z / 19 / Z$ ), is supported by the University of Bristol NIHR Biomedical Research Centre (BRC-

397 1215-2001), the MRC Integrative Epidemiology Unit (MC_UU_00011) and works within the CRUK

398 Integrative Cancer Epidemiology Programme (C18281/A19169). DG, PM, SZ and DR are supported

399 by the NIHR Biomedical Research Centre at University Hospitals Bristol NHS Foundation Trust.

400 None of the named funders influenced the study design, data collection, analyses or interpretation of

401 results. The views expressed in this paper are those of the authors and not necessarily of any of the

402 funders, the National Health Service or the Department of Health. 
medRxiv preprint doi: https://doi.org/10.1101/2020.06.16.20133116; this version posted June 18, 2020. The copyright holder for this preprint (which was not certified by peer review) is the author/funder, who has granted medRxiv a license to display the preprint in perpetuity.

It is made available under a CC-BY-NC-ND 4.0 International license .

403

404

405

406

407

408

409

410

411

412

413

414

415

416

417

418

419

420

421

422

423

424

425

426

427

428

429

430

431

432

433

434

435

436

437

438

439

440

441

442

443

444

445

446

447

448

449

450

\section{References}

1. Holmes, E.A., et al., Multidisciplinary research priorities for the COVID-19 pandemic: a call for action for mental health science. The Lancet Psychiatry, 2020.

2. $\quad$ Rogers, J.P., et al., Psychiatric and neuropsychiatric presentations associated with severe coronavirus infections: a systematic review and meta-analysis with comparison to the COVID-19 pandemic. The Lancet Psychiatry, 2020.

3. Brooks, S.K., et al., The psychological impact of quarantine and how to reduce it: rapid review of the evidence. The Lancet, 2020. 395(10227): p. 912-920.

4. Lam, M.H., et al., Mental Morbities and Chronic Fatigue in Severe Acute Respiratory Syndrome Survivors: Long-term Follow-up. Arch Intern Med, 2009. 169(22): p. 2142-2147.

5. Cheung, Y.T., P.H. Chau, and P.S. Yip, A revisit on older adults suicides and Severe Acute Respiratory Syndrome (SARS) epidemic in Hong Kong. Int J Geriatr Psychiatry, 2008. 23(12): p. 1231-8.

6. Mak, I.W., et al., Long-term psychiatric morbidities among SARS survivors. Gen Hosp Psychiatry, 2009. 31(4): p. 318-26.

7. Lau, J.T.F., et al., Avoidance behaviors and negative psychological responses in the general population in the initial stage of the H1N1 pandemic in Hong Kong. BMC Infectious Diseases, 2010. 10(139).

8. Tsang, H.W.H., R.J. Scudds, and E.Y.L. Chan, Psychosocial Impact of SARS. Emerging Infectious Diseases, 2004. 10(7).

9. Xiang, Y.-T., et al., Timely mental health care for the 2019 novel coronavirus outbreak is urgently needed. The Lancet Psychiatry, 2020. 7(3): p. 228-229.

10. Qiu, J., et al., A nationwide survey of psychological distress among Chinese people in the COVID-19 epidemic: implications and policy recommendations. Gen Psychiatr, 2020. 33(2): p. e100213.

11. Lai, J., et al., Factors Associated With Mental Health Outcomes Among Health Care Workers Exposed to Coronavirus Disease 2019. JAMA Netw Open, 2020. 3(3): p. e203976.

12. Office for National Statistics. Personal and economic well-being in Great Britain: May 2020. 2020 4th May 2020 [cited 2020 16th May]; Available from:

https://www.ons.gov.uk/peoplepopulationandcommunity/wellbeing/bulletins/personaland economicwellbeingintheuk/may2020.

13. Fancourt, D., et al. COVID-19 Social Study - Results Release 10. 2020 30th May 2020].

14. Pierce, M., et al., Says who? The significance of sampling in mental health surveys during COVID-19. The Lancet Psychiatry, 2020.

15. Gunnell, D., et al., Suicide risk and prevention during the COVID-19 pandemic. The Lancet Psychiatry, 2020.

16. Wright, L., A. Steptoe, and D. Fancourt, How are adversities during COVID-19 affecting mental health? Differential associations for worries and experiences and implications for policy. medRxiv, 2020.

17. Boyd, A., et al., Cohort Profile: the 'children of the 90s'--the index offspring of the Avon Longitudinal Study of Parents and Children. Int J Epidemiol, 2013. 42(1): p. 111-27.

18. Fraser, A., et al., Cohort Profile: the Avon Longitudinal Study of Parents and Children: ALSPAC mothers cohort. Int J Epidemiol, 2013. 42(1): p. 97-110.

19. Northstone, K., et al., The Avon Longitudinal Study of Parents and Children (ALSPAC): an update on the enrolled sample of index children in 2019. Wellcome Open Res, 2019. 4: p. 51.

20. Smith, B.H., et al., Cohort Profile: Generation Scotland: Scottish Family Health Study (GS:SFHS). The study, its participants and their potential for genetic research on health and illness. Int J Epidemiol, 2013. 42(3): p. 689-700. 
medRxiv preprint doi: https://doi.org/10.1101/2020.06.16.20133116; this version posted June 18, 2020. The copyright holder for this preprint (which was not certified by peer review) is the author/funder, who has granted medRxiv a license to display the preprint in perpetuity.

It is made available under a CC-BY-NC-ND 4.0 International license .

21. Navrady, L.B., et al., Cohort Profile: Stratifying Resilience and Depression Longitudinally (STRADL): a questionnaire follow-up of Generation Scotland: Scottish Family Health Study (GS:SFHS). Int J Epidemiol, 2018. 47(1): p. 13-14g.

22. Northstone, K., et al., The Avon Longitudinal Study of Parents and Children - A resource for COVID-19 research: Questionnaire data capture April-May 2020. Wellcome Open Research, 2020. 5.

23. Angold, A., et al., Development of a short questionnaire for use in epidemiological studies of depression in children and adolescents. International Journal of Methods in Psychiatric Research, 1995. 5(4): p. 237-249.

24. Kroenke, K., R.L. Spitzer, and J.B. Williams, The PHQ-9: Validity of a Brief Depression Severity Measure. J Gen Intern Med, 2001. 16(9): p. 606-613.

25. Spitzer, R.L., et al., A Brief Measure for Assessing Generalized Anxiety Disorder. Arch Intern Med, 2006. 166: p. 1092-1097.

26. Stewart-Brown, S., et al., Internal construct validity of the Warwick-Edinburgh Mental Wellbeing Scale (WEMWBS): a Rasch analysis using data from the Scottish Health Education Population Survey. Health Qual Life Outcomes, 2009. 7: p. 15.

27. Royston, P. and I.R. White, Multiple Imputation by Chained Equations (MICE): Implementation in Stata. Journal of Statistical Software, 2011. 45(4).

28. Lewis, G., et al., The clinical effectiveness of sertraline in primary care and the role of depression severity and duration (PANDA): a pragmatic, double-blind, placebo-controlled randomised trial. The Lancet Psychiatry, 2019. 6(11): p. 903-914.

29. Carpenter, J.K., et al., Cognitive behavioral therapy for anxiety and related disorders: A metaanalysis of randomized placebo-controlled trials. Depress Anxiety, 2018. 35(6): p. 502-514.

30. Sutin, A.R., et al., The trajectory of depressive symptoms across the adult life span. JAMA Psychiatry, 2013. 70(8): p. 803-11.

31. Malhi, G.S. and J.J. Mann, Depression. Lancet, 2018. 392: p. 2299-2312.

32. Lukmanji, A., et al., Seasonal variation in symptoms of depression: A Canadian population based study. J Affect Disord, 2019. 255: p. 142-149.

33. Druss, B.G., Addressing the COVID-19 Pandemic in Populations With Serious Mental IIIness. JAMA Psychiatry, 2020.

34. Yao, H., J.-H. Chen, and Y.-F. Xu, Patients with mental health disorders in the COVID-19 epidemic. The Lancet Psychiatry, 2020. 7(4).

35. Shore, J.H., C.D. Schneck, and M.C. Mishkind, Telepsychiatry and the Coronavirus Disease 2019 Pandemic-Current and Future Outcomes of the Rapid Virtualization of Psychiatric Care. JAMA Psychiatry, 2020. 
Tables and figures

\begin{tabular}{|c|c|c|c|}
\hline & ALSPAC-G0 & ALSPAC-G1 & Generation Scotland \\
\hline & Measure & Measure & Measure \\
\hline \multicolumn{4}{|l|}{ Sociodemographic factors } \\
\hline Sex & Questionnaire item & Questionnaire item & Questionnaire item \\
\hline Age & Questionnaire item & Questionnaire item & Questionnaire item \\
\hline Educational background & Questionnaire item & Questionnaire item & Questionnaire item \\
\hline Income & Questionnaire item & Questionnaire item & Questionnaire item \\
\hline Deprivation status & Indexes of multiple deprivation & Indexes of multiple deprivation & Indexes of multiple deprivation \\
\hline Recent financial problems & Questionnaire item & Questionnaire item & Questionnaire item \\
\hline Partner emotional abuse & Life events questionnaire & Not assessed & Not assessed \\
\hline Parent with young children & Not assessed & Questionnaire item & Questionnaire item \\
\hline \multicolumn{4}{|l|}{ Biological factors } \\
\hline Obesity & $\begin{array}{l}\text { BMI > } 30 \text { assessed at a research } \\
\text { clinic }\end{array}$ & $\begin{array}{l}\text { BMI > } 30 \text { assessed at a research } \\
\text { clinic }\end{array}$ & $\begin{array}{l}\text { BMI > } 30 \text { assessed at a research } \\
\text { clinic }\end{array}$ \\
\hline Asthma & Questionnaire item & Questionnaire item & Questionnaire item \\
\hline \multicolumn{4}{|l|}{ COVID-19 specific factors } \\
\hline Infection status & Questionnaire item & Questionnaire item & Questionnaire item \\
\hline Isolation status & Questionnaire item & Questionnaire item & Not assessed \\
\hline Living alone & Questionnaire item & Questionnaire item & Questionnaire item \\
\hline No access to a garden & Questionnaire item & Questionnaire item & Questionnaire item \\
\hline Health care worker & Questionnaire item & Questionnaire item & Not assessed \\
\hline Key worker & Questionnaire item & Questionnaire item & Questionnaire item \\
\hline \multicolumn{4}{|c|}{ Baseline mental health measures } \\
\hline Depressive symptoms & $\begin{array}{l}\text { Edinburgh postnatal depression } \\
\text { scale }\end{array}$ & $\begin{array}{l}\text { Short mood and feelings } \\
\text { questionnaire }\end{array}$ & $\begin{array}{l}\text { General health questionnaire - } \\
\text { depression }\end{array}$ \\
\hline Anxiety & $\begin{array}{l}\text { Spielberger state-trait anxiety } \\
\text { inventory }\end{array}$ & $\begin{array}{l}\text { Generalised anxiety disorder } \\
\text { assessment }\end{array}$ & $\begin{array}{l}\text { General health questionnaire - } \\
\text { anxiety }\end{array}$ \\
\hline Mental wellbeing & Not assessed & $\begin{array}{l}\text { Warwick-Edinburgh mental } \\
\text { wellbeing scale }\end{array}$ & Not assessed \\
\hline
\end{tabular}




\section{Psychiatric or mental health factors}

Probable major depression (MDD)

Probable generalised anxiety disorder (GAD)

Life events questionnaire

Life events questionnaire

Psychosis like experiences

Not assessed

Disordered eating

Life events questionnaire

Obsessive compulsive disorder traits (OCD

Autistic traits

Not assessed

Personality disorder traits

Not assessed

Karolinska scales of personality

History of alcohol misuse

Current smokers (tobacco)

Cognitive styles

Difficulties accessing mental health information

Neuroticism

Self-harm history

Depression polygenic risk score (PRS)
Alcohol use disorders

identification test

Questionnaire items

Negative schemas questionnaire

Not assessed

Not assessed

Not assessed

Constructed from a recent

GWAS on depression
Clinical interview schedule -

revised

Clinical interview schedule -

revised

Psychosis like symptoms

interview

Questionnaire items consistent

with DSM-V frequency

Obsessive-compulsive

inventory

Social responsiveness scale

Standardised assessment of

personality: abbreviated scale

Alcohol use disorders

identification test

Questionnaire items

Cognitive styles questionnaire

Public health questionnaire

Big five factors of personality neuroticism

Questionnaire items

Constructed from a recent

GWAS on depression
Structured clinical interview for

DSM-IV

Not assessed

Schizotypal personality questionnaire

Not assessed

Not assessed

Not assessed

Not assessed

Questionnaire item

Questionnaire items

Brief resilience scale

Not assessed

Eysenck personality

questionnaire - neuroticism

Linkage to medical records

Constructed from a recent

GWAS on depression

Table 1. Baseline mental health measures and factors assessed in ALSPAC and Generation Scotland. 
Depression standardised estimates (95\% CIs), $P$

\begin{tabular}{|c|c|c|c|c|c|c|}
\hline & $\begin{array}{l}\text { ALSPAC G0 } \\
(n=3579)\end{array}$ & $\begin{array}{l}\text { ALSPAC G1 } \\
(\mathrm{n}=2872)\end{array}$ & $\begin{array}{l}\text { Gen Scot } \\
(n=4208)\end{array}$ & $\begin{array}{l}\text { ALSPAC G0 } \\
(\mathrm{n}=3579)\end{array}$ & $\begin{array}{l}\text { ALSPAC G1 } \\
(\mathrm{n}=2872)\end{array}$ & $\begin{array}{l}\text { Gen Scot } \\
(n=4208)\end{array}$ \\
\hline \multicolumn{7}{|l|}{$\begin{array}{l}\text { Sociodemographic } \\
\text { factors }\end{array}$} \\
\hline $\begin{array}{l}\text { Sex (female) } \\
(76 \% / 72 \% / 64 \%)^{*}\end{array}$ & $\begin{array}{l}0.28(0.21,0.34) \\
P=1.46 \times 10^{-19}\end{array}$ & $\begin{array}{l}0.22(0.15,0.29) \\
P=1.20 \times 10^{-9}\end{array}$ & $\begin{array}{l}0.27(0.22,0.32) \\
P=4.07 \times 10^{-22}\end{array}$ & $\begin{array}{l}0.26(0.20,0.32) \\
P=7.87 \times 10^{-17}\end{array}$ & $\begin{array}{l}0.40(0.33,0.48) \\
P=3.57 \times 10^{-23}\end{array}$ & $\begin{array}{l}0.18(0.12,0.23) \\
P=6.63 \times 10^{-10}\end{array}$ \\
\hline $\begin{array}{l}\text { Age (older ages) } \\
\text { (scale variable)** }\end{array}$ & $\begin{array}{l}-0.02(-0.03,-0.01) \\
P=2.08 \times 10^{-8}\end{array}$ & $\begin{array}{l}-0.01(-0.07,0.04) \\
P=0.643\end{array}$ & $\begin{array}{l}-0.02(-0.02,-0.02) \\
P=4.57 \times 10^{-46}\end{array}$ & $\begin{array}{l}-0.02(-0.03,-0.02) \\
P=4.82 \times 10^{-12}\end{array}$ & $\begin{array}{l}0.00(-0.06,0.07) \\
P=0.945\end{array}$ & $\begin{array}{l}-0.01(-0.02,-0.01) \\
P=1.25 \times 10^{-30}\end{array}$ \\
\hline $\begin{array}{l}\text { Lower educational } \\
\text { background } \\
(11 \% / 16 \% / 13 \%)\end{array}$ & $\begin{array}{l}0.23(0.12,0.35) \\
P=0.00008\end{array}$ & $\begin{array}{l}0.05(-0.04,0.15) \\
P=0.276\end{array}$ & $\begin{array}{l}0.15(0.06,0.24) \\
P=0.001\end{array}$ & $\begin{array}{l}0.14(0.03,0.25) \\
P=0.016\end{array}$ & $\begin{array}{l}0.16(0.06,0.26) \\
P=0.002\end{array}$ & $\begin{array}{l}0.09(0.00,0.18) \\
P=0.061\end{array}$ \\
\hline $\begin{array}{l}\text { Higher income } \\
\text { (scale variable) }\end{array}$ & $\begin{array}{l}-0.04(-0.06,-0.03) \\
P=6.22 \times 10^{-8}\end{array}$ & $\begin{array}{l}-0.01(-0.04,0.01) \\
P=0.328\end{array}$ & $\begin{array}{l}-0.10(-0.13,-0.08) \\
P=5.14 \times 10^{-16}\end{array}$ & $\begin{array}{l}-0.01(-0.03,0.00) \\
P=0.052\end{array}$ & $\begin{array}{l}-0.04(-0.07,-0.01) \\
P=0.008\end{array}$ & $\begin{array}{l}-0.07(-0.09,-0.04) \\
P=5.46 \times 10^{-7}\end{array}$ \\
\hline $\begin{array}{l}\text { Worse deprivation status } \\
\text { (scale variable) }\end{array}$ & $\begin{array}{l}0.07(0.04,0.10) \\
P=0.00002\end{array}$ & $\begin{array}{l}0.01(-0.01,0.04) \\
P=0.319\end{array}$ & $\begin{array}{l}0.06(0.04,0.09) \\
P=7.33 \times 10^{-7}\end{array}$ & $\begin{array}{l}0.05(0.02,0.08) \\
P=0.001\end{array}$ & $\begin{array}{l}0.04(0.01,0.07) \\
P=0.005\end{array}$ & $\begin{array}{l}0.04(0.02,0.06) \\
P=0.001\end{array}$ \\
\hline $\begin{array}{l}\text { Financial problems } \\
(11 \% / 10 \% / 4 \%)\end{array}$ & $\begin{array}{l}0.29(0.15,0.43) \\
P=0.00005\end{array}$ & $\begin{array}{l}0.14(0.03,0.26) \\
P=0.015\end{array}$ & $\begin{array}{l}0.38(0.18,0.58) \\
P=0.0002\end{array}$ & $\begin{array}{l}0.20(0.07,0.32) \\
P=0.011\end{array}$ & $\begin{array}{l}0.24(0.12,0.36) \\
P=0.0002\end{array}$ & $\begin{array}{l}0.20(0.00,0.39) \\
P=0.049\end{array}$ \\
\hline $\begin{array}{l}\text { Partner emotional abuse } \\
(8 \% / \mathrm{Na} / \mathrm{Na})\end{array}$ & $\begin{array}{l}0.36(0.18,0.53) \\
P=0.00005\end{array}$ & Not assessed & Not assessed & $\begin{array}{l}0.29(0.13,0.46) \\
P=0.001\end{array}$ & Not assessed & Not assessed \\
\hline $\begin{array}{l}\text { Parent with young } \\
\text { children } \\
\text { (Na / } 11 \% / 11 \%) \\
\text { Biological factors }\end{array}$ & Not assessed & $\begin{array}{l}0.03(-0.07,0.13) \\
P=0.570\end{array}$ & $\begin{array}{l}-0.03(-0.14,0.08) \\
P=0.617\end{array}$ & Not assessed & $\begin{array}{l}0.19(0.08,0.30) \\
P=0.001\end{array}$ & $\begin{array}{l}0.05(-0.05,0.16) \\
P=0.353\end{array}$ \\
\hline $\begin{array}{l}\text { Obesity } \\
(18 \% / 14 \% / 20 \%)\end{array}$ & $\begin{array}{l}0.22(0.12,0.32) \\
P=0.00001\end{array}$ & $\begin{array}{l}0.18(0.06,0.31) \\
P=0.004\end{array}$ & $\begin{array}{l}0.32(0.24,0.40) \\
P=1.09 \times 10^{-14}\end{array}$ & $\begin{array}{l}0.14(0.04,0.25) \\
P=0.005\end{array}$ & $\begin{array}{l}0.15(0.03,0.27) \\
P=0.012\end{array}$ & $\begin{array}{l}0.10(0.02,0.18) \\
P=0.010\end{array}$ \\
\hline $\begin{array}{l}\text { Asthma } \\
(16 \% / 10 \% / 10 \%) \\
\text { COVID-19 specific } \\
\text { factors }\end{array}$ & $\begin{array}{l}0.07(-0.02,0.16) \\
P=0.127\end{array}$ & $\begin{array}{l}0.08(-0.04,0.20) \\
P=0.196\end{array}$ & $\begin{array}{l}0.18(0.07,0.28) \\
P=0.001\end{array}$ & $\begin{array}{l}0.07(-0.02,0.16) \\
P=0.14\end{array}$ & $\begin{array}{l}0.21(0.07,0.35) \\
P=0.003\end{array}$ & $\begin{array}{l}0.12(0.02,0.22) \\
P=0.016\end{array}$ \\
\hline $\begin{array}{l}\text { COVID-19 infection } \\
(12 \% / 16 \% / 8 \%)\end{array}$ & $\begin{array}{l}0.18(0.07,0.28) \\
P=0.001\end{array}$ & $\begin{array}{l}0.09(0.00,0.17) \\
P=0.045\end{array}$ & $\begin{array}{l}0.17(0.05,0.29) \\
P=0.004\end{array}$ & $\begin{array}{l}0.16(0.06,0.27) \\
P=0.003\end{array}$ & $\begin{array}{l}0.08(-0.02,0.17) \\
P=0.112\end{array}$ & $\begin{array}{l}0.10(-0.02,0.21) \\
P=0.101\end{array}$ \\
\hline $\begin{array}{l}\text { Self-isolation } \\
(19 \% / 25 \% / \mathrm{Na})\end{array}$ & $\begin{array}{l}0.20(0.11,0.29) \\
P=6.64 \times 10^{-6}\end{array}$ & $\begin{array}{l}0.15(0.08,0.22) \\
P=0.00004\end{array}$ & Not assessed & $\begin{array}{l}0.13(0.04,0.27) \\
P=0.003\end{array}$ & $\begin{array}{l}0.17(0.09,0.25) \\
P=0.00003\end{array}$ & Not assessed \\
\hline
\end{tabular}




\begin{tabular}{|c|c|c|c|c|c|c|}
\hline $\begin{array}{l}\text { Living alone } \\
(8 \% / 6 \% / 16 \%)\end{array}$ & $\begin{array}{l}0.45(0.30,0.59) \\
P=4.80 \times 10^{-9}\end{array}$ & $\begin{array}{l}0.20(0.06,0.34) \\
P=0.005\end{array}$ & $\begin{array}{l}0.19(0.11,0.27) \\
P=4.47 \times 10^{-6}\end{array}$ & $\begin{array}{l}-0.06(-0.19,0.07) \\
P=0.372\end{array}$ & $\begin{array}{l}0.06(-0.08,0.21) \\
P=0.392\end{array}$ & $\begin{array}{l}-0.03(-0.11,0.06) \\
P=0.539\end{array}$ \\
\hline $\begin{array}{l}\text { No access to a garden } \\
(2 \% / 18 \% / 8 \%)\end{array}$ & $\begin{array}{l}0.47(0.09,0.85) \\
P=0.016\end{array}$ & $\begin{array}{l}0.16(0.07,0.24) \\
P=0.0002\end{array}$ & $\begin{array}{l}0.24(0.12,0.37) \\
P=0.0001\end{array}$ & $\begin{array}{l}-0.07(-0.35,0.21) \\
P=0.62\end{array}$ & $\begin{array}{l}0.05(-0.04,0.14) \\
P=0.235\end{array}$ & $\begin{array}{l}0.16(0.04,0.28) \\
P=0.007\end{array}$ \\
\hline $\begin{array}{l}\text { Health care worker } \\
(11 \% / 12 \% \text { / NA) }\end{array}$ & $\begin{array}{l}0.01(-0.09,0.10) \\
P=0.901\end{array}$ & $\begin{array}{l}-0.02(-0.12,0.08) \\
P=0.683\end{array}$ & Not assessed & $\begin{array}{l}-0.03(-0.13,0.07) \\
P=0.597\end{array}$ & $\begin{array}{l}0.02(-0.08,0.13) \\
P=0.652\end{array}$ & Not assessed \\
\hline $\begin{array}{l}\text { Key worker } \\
(32 \% / 39 \% / 22 \%) \\
\text { Psychiatric or mental } \\
\text { health factors }\end{array}$ & $\begin{array}{l}0.04(-0.03,0.11) \\
P=0.214\end{array}$ & $\begin{array}{l}-0.09(-0.15,-0.02) \\
P=0.008\end{array}$ & $\begin{array}{l}-0.05(-0.13,0.02) \\
P=0.178\end{array}$ & $\begin{array}{l}0.03(-0.04,0.10) \\
P=0.441\end{array}$ & $\begin{array}{l}0.02(-0.05,0.09) \\
P=0.631\end{array}$ & $\begin{array}{l}0.04(-0.03,0.12) \\
P=0.266\end{array}$ \\
\hline $\begin{array}{l}\text { Probable MDD } \\
(8 \% / 14 \% / 14 \%)\end{array}$ & $\begin{array}{l}0.38(0.22,0.54) \\
P=2.29 \times 10^{-6}\end{array}$ & $\begin{array}{l}0.31(0.20,0.42) \\
P=3.18 \times 10^{-8}\end{array}$ & $\begin{array}{l}0.39(0.29,0.49) \\
P=1.84 \times 10^{-13}\end{array}$ & $\begin{array}{l}0.26(0.11,0.40) \\
P=0.0005\end{array}$ & $\begin{array}{l}0.49(0.39,0.62) \\
P=1.33 \times 10^{-16}\end{array}$ & $\begin{array}{l}0.27(0.17,0.38) \\
P=7.03 \times 10^{-7}\end{array}$ \\
\hline $\begin{array}{l}\text { Probable GAD } \\
(7 \% / 13 \% / \mathrm{Na})\end{array}$ & $\begin{array}{l}0.26(0.11,0.42) \\
P=0.001\end{array}$ & $\begin{array}{l}0.14(0.03,0.25) \\
P=0.010\end{array}$ & Not assessed & $\begin{array}{l}0.25(0.09,0.40) \\
P=0.002\end{array}$ & $\begin{array}{l}0.50(0.39,0.62) \\
P=2.72 \times 10^{-17}\end{array}$ & Not assessed \\
\hline $\begin{array}{l}\text { Psychosis like } \\
\text { experiences } \\
\text { (Na / 15\% / scale) }\end{array}$ & Not assessed & $\begin{array}{l}0.17(0.07,0.27) \\
P=0.001\end{array}$ & $\begin{array}{l}0.15(0.11,0.19) \\
P=3.72 \times 10^{-14}\end{array}$ & Not assessed & $\begin{array}{l}0.25(0.15,0.36) \\
P=4.74 \times 10^{-6}\end{array}$ & $\begin{array}{l}0.12(0.08,0.16) \\
P=9.59 \times 10^{-9}\end{array}$ \\
\hline $\begin{array}{l}\text { Disordered eating } \\
(3 \% / 9 \% / \mathrm{Na})\end{array}$ & $\begin{array}{l}0.09(-0.14,0.32) \\
P=0.689\end{array}$ & $\begin{array}{l}0.21(0.09,0.34) \\
P=0.0005\end{array}$ & Not assessed & $\begin{array}{l}0.08(-0.16,0.32) \\
P=0.510\end{array}$ & $\begin{array}{l}0.26(0.12,0.40) \\
P=0.0002\end{array}$ & Not assessed \\
\hline $\begin{array}{l}\text { OCD traits } \\
\text { (scale variable) }\end{array}$ & Not assessed & $\begin{array}{l}0.05(0.01,0.09) \\
P=0.027\end{array}$ & Not assessed & Not assessed & $\begin{array}{l}0.15(0.11,0.19) \\
P=8.28 \times 10^{-13}\end{array}$ & Not assessed \\
\hline $\begin{array}{l}\text { Autistic traits } \\
(\mathrm{Na} / 7 \% / \mathrm{Na})\end{array}$ & Not assessed & $\begin{array}{l}0.19(0.05,0.34) \\
P=0.008\end{array}$ & Not assessed & Not assessed & $\begin{array}{l}0.35(0.20,0.51) \\
P=5.18 \times 10^{-6}\end{array}$ & Not assessed \\
\hline $\begin{array}{l}\text { Personality disorder } \\
\text { traits } \\
(11 \% / 11 \% / \mathrm{Na})\end{array}$ & $\begin{array}{l}0.32(0.19,0.45) \\
P=1.67 \times 10^{-6}\end{array}$ & $\begin{array}{l}0.09(0.04,0.23) \\
P=0.169\end{array}$ & Not assessed & $\begin{array}{l}0.15(0.02,0.27) \\
P=0.021\end{array}$ & $\begin{array}{l}0.27(0.14,0.40) \\
P=0.00008\end{array}$ & Not assessed \\
\hline $\begin{array}{l}\text { History of alcohol } \\
\text { misuse } \\
(17 \% / 9 \% / 16 \%)\end{array}$ & $\begin{array}{l}0.04(-0.05,0.13) \\
P=0.367\end{array}$ & $\begin{array}{l}0.13(0.01,0.25) \\
P=0.040\end{array}$ & $\begin{array}{l}0.02(-0.06,0.10) \\
P=0.598\end{array}$ & $\begin{array}{l}0.09(0.00,0.18) \\
P=0.047\end{array}$ & $\begin{array}{l}0.20(0.07,0.33) \\
P=0.003\end{array}$ & $\begin{array}{l}-0.02(-0.10,0.06) \\
P=0.569\end{array}$ \\
\hline $\begin{array}{l}\text { Current smokers } \\
\text { (tobacco) } \\
(29 \% / 12 \% / 10 \%)\end{array}$ & $\begin{array}{l}0.18(0.10,0.25) \\
P=7.58 \times 10^{-6}\end{array}$ & $\begin{array}{l}0.02(-0.09,0.13) \\
P=0.690\end{array}$ & $\begin{array}{l}0.30(0.19,0.41) \\
P=1.23 \times 10^{-7}\end{array}$ & $\begin{array}{l}0.12(0.05,0.20) \\
P=0.001\end{array}$ & $\begin{array}{l}0.10(-0.01,0.21) \\
P=0.085\end{array}$ & $\begin{array}{l}0.18(0.08,0.29) \\
P=0.001\end{array}$ \\
\hline $\begin{array}{l}\text { Negative cognitive } \\
\text { styles } \\
\text { (scale variable) }\end{array}$ & $\begin{array}{l}0.21(0.16,0.25) \\
P=1.07 \times 10^{-18}\end{array}$ & $\begin{array}{l}0.09(0.05,0.13) \\
P=0.00004\end{array}$ & $\begin{array}{l}0.22(0.19,0.26) \\
P=2.97 \times 10^{-32}\end{array}$ & $\begin{array}{l}0.16(0.12,0.20) \\
P=3.07 \times 10^{-14}\end{array}$ & $\begin{array}{l}0.07(0.02,0.12) \\
P=0.003\end{array}$ & $\begin{array}{l}0.19(0.15,0.22) \\
P=5.39 \times 10^{-21}\end{array}$ \\
\hline
\end{tabular}




\begin{tabular}{|c|c|c|c|c|c|c|}
\hline $\begin{array}{l}\text { Difficulties accessing } \\
\text { mental health info } \\
(\mathrm{Na} / 23 \% / \mathrm{Na})\end{array}$ & Not assessed & $\begin{array}{l}0.12(0.03,0.20) \\
P=0.009\end{array}$ & Not assessed & Not assessed & $\begin{array}{l}0.28(0.19,0.36) \\
P=1.93 \times 10^{-9}\end{array}$ & Not assessed \\
\hline $\begin{array}{l}\text { Higher neuroticism } \\
\text { (scale variable) }\end{array}$ & Not assessed & $\begin{array}{l}0.04(0.01,0.09) \\
P=0.015\end{array}$ & $\begin{array}{l}0.22(0.19,0.26) \\
P=3.00 \times 10^{-42}\end{array}$ & Not assessed & $\begin{array}{l}0.11(0.07,0.15) \\
P=7.33 \times 10^{-7}\end{array}$ & $\begin{array}{l}0.21(0.18,0.25) \\
P=1.97 \times 10^{-31}\end{array}$ \\
\hline $\begin{array}{l}\text { Self-harm history } \\
(\mathrm{Na} / 24 \% / 2 \%)\end{array}$ & Not assessed & $\begin{array}{l}0.15(0.06,0.23) \\
P=0.001\end{array}$ & $\begin{array}{l}0.55(0.22,0.88) \\
P=0.001\end{array}$ & Not assessed & $\begin{array}{l}0.19(0.09,0.28) \\
P=0.0002\end{array}$ & $\begin{array}{l}0.58(0.28,0.88) \\
P=1.97 \times 10^{-8}\end{array}$ \\
\hline $\begin{array}{l}\text { Depression PRS } * * * \\
\text { (scale variable) }\end{array}$ & $\begin{array}{l}0.09(0.05,0.13) \\
P=0.00002 \\
(\mathrm{n}=1906)\end{array}$ & $\begin{array}{l}0.03(-0.02,0.07) \\
P=0.224 \\
(\mathrm{n}=1592)\end{array}$ & $\begin{array}{l}0.05(0.02,0.08) \\
P=0.0002 \\
(\mathrm{n}=3849)\end{array}$ & $\begin{array}{l}0.09(0.05,0.14) \\
P=0.00004 \\
(\mathrm{n}=2071)\end{array}$ & $\begin{array}{l}0.00(-0.05,0.05) \\
P=0.993 \\
(\mathrm{n}=1329)\end{array}$ & $\begin{array}{l}0.06(0.03,0.09) \\
P=0.00002 \\
(\mathrm{n}=3832)\end{array}$ \\
\hline
\end{tabular}

Table 2. Associations between baseline risk factors and depression and anxiety using the imputed samples. Results are standardised estimates for depression and anxiety, adjusted for prior depression or anxiety, sex, age and when the COVID-19 questionnaire was completed. *Indicates the \% of individuals with caseness for ALSPAC-G0 / ALSPAC-G1 / GS respectively. **Indicates a continuous scale was used so no proportions are given. ***Indicates this was on complete case analysis only. MDD: major depressive disorder; GAD: generalised anxiety disorder; OCD: obsessive compulsive disorder; PRS: polygenic risk score. 
Figure 1. Mental health during COVID-19 in ALSPAC-G0, ALSPAC-G1 and Generation Scotland (GS). Figure 1A (top left) shows probable depression, probable generalised anxiety disorder (GAD) and lower wellbeing by each cohort. Figure 1B (top right) shows probable depression by age groups assessed using the SMFQ in ALSPAC and PHQ-9 in GS. Figure 1C (bottom left) shows probable GAD by age groups assessed by the GAD-7. Figure 1D shows lower wellbeing by age groups assessed by the SWEMWBS. Note, ALSPAC-G1 $(n=2812)$ were categorised as 18-40, even though the max age of this cohort is 29 years. Age in ALSPAC-G0 was split by the following: Age 40-49 ( $\mathrm{n}=89)$, Age 50-59 ( $\mathrm{n}=2105)$, Age 60-69 ( $\mathrm{n}=1455)$ and Age 70+ ( $\mathrm{n}=71)$. In GS, Age was split by the following: Age 18-40 ( $\mathrm{n}=356)$, Age 40-49 (n=534), Age 50-59 ( $\mathrm{n}=964)$, Age 60-69 $(\mathrm{n}=1526)$ and Age 70+ $(\mathrm{n}=853)$.

Figure 2. Changes in mental health across baseline (pre-pandemic) to COVID-19 in ALSPAC-G1. Figure 2A (top left) shows changes in probable depression as assessed by the SMFQ. Figure 2B (top right) shows changes in probable GAD assessed by the GAD-7 at age 22 and CISR GAD at ages 18 and 24 . Figure $2 \mathrm{C}$ (bottom left) shows changes in lower wellbeing assessed by the SWEMWBS.

Figure 3. Item level changes in mental health between the most recent baseline and COVID-19 in ALSPAC-G1. Figure 3A (top left) shows how items of the SMFQ (depression) vary from the most recent baseline (Age 26) to COVID-19. Figure 3B (top right) shows how items of the GAD-7 (anxiety) vary from the most recent baseline (Age 22) to COVID-19. Figure 3C (bottom left) shows high items from the SWEMWBS (mental wellbeing) vary from the most recent baseline (Age 24) to COVID-19.

Figure 4. Associations between baseline and COVID-19 factors and depression during COVID-19, adjusted for baseline depression, sex, age and when the COVID-19 questionnaire was completed, using imputed data. Estimates refer to a standard deviation increase in depression, over and above depression at baseline. Figure 4A (top left) shows associations between baseline sociodemographic factors and depression during COVID-19. Figure 4B (top right) shows associations between baseline physical health and COVID-19 specific factors and depression during COVID-19. Figure 4C (bottom left) and Figure 4D (bottom right) shows associations between baseline mental health factors and depression during COVID-19.

Figure 5. Associations between baseline and COVID-19 factors and anxiety during COVID-19, adjusted for baseline anxiety, sex, age and when the COVID19 questionnaire was completed, using imputed data. Estimates refer to a standard deviation increase in anxiety, over and above anxiety at baseline. Figure 4A (top left) shows associations between baseline sociodemographic factors and anxiety during COVID-19. Figure 4B (top right) shows associations between baseline physical health and COVID-19 specific factors and anxiety during COVID-19. Figure 4C (bottom left) and Figure 4D (bottom right) shows associations between baseline mental health factors and anxiety during COVID-19. 

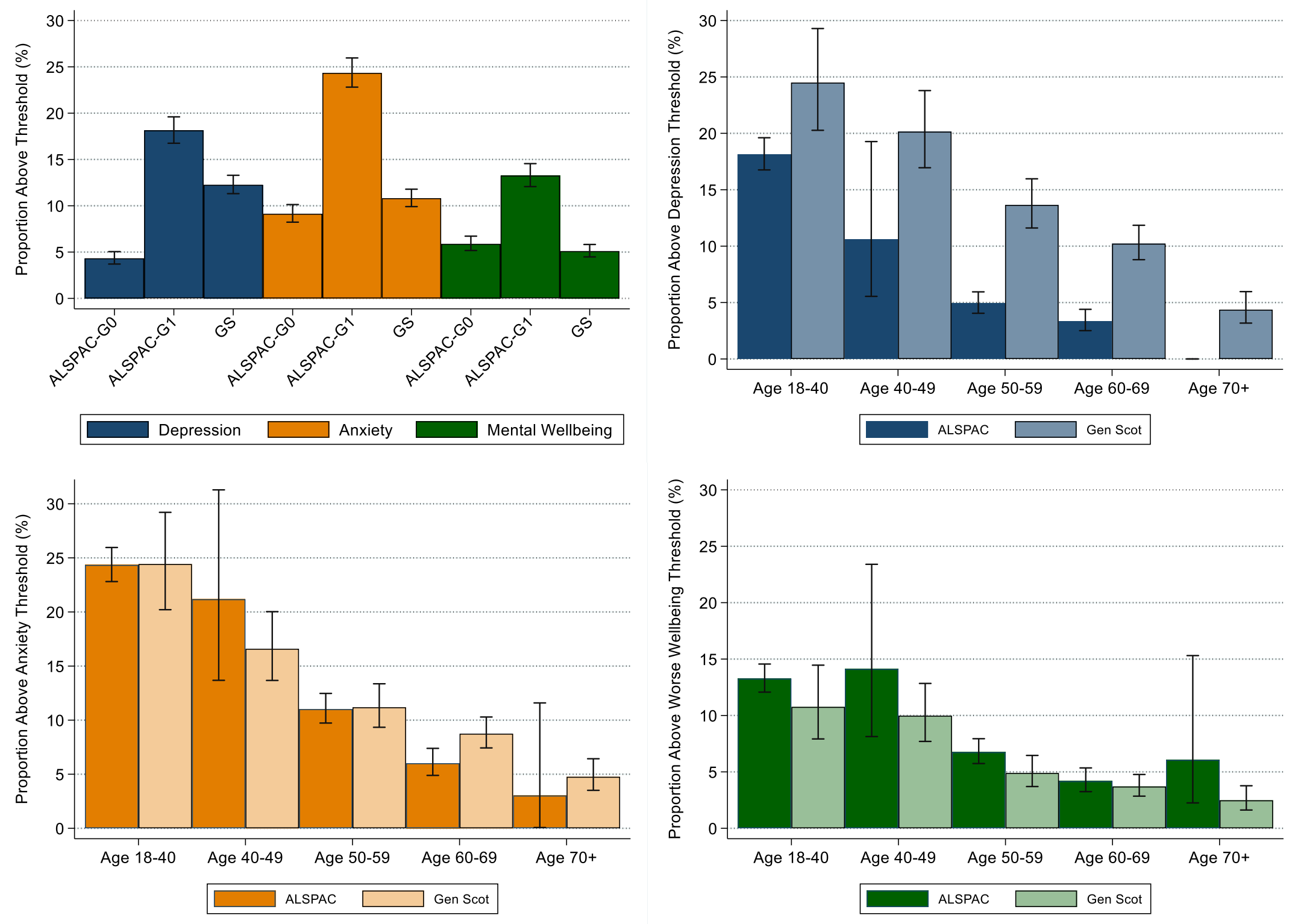

Figure 1. 

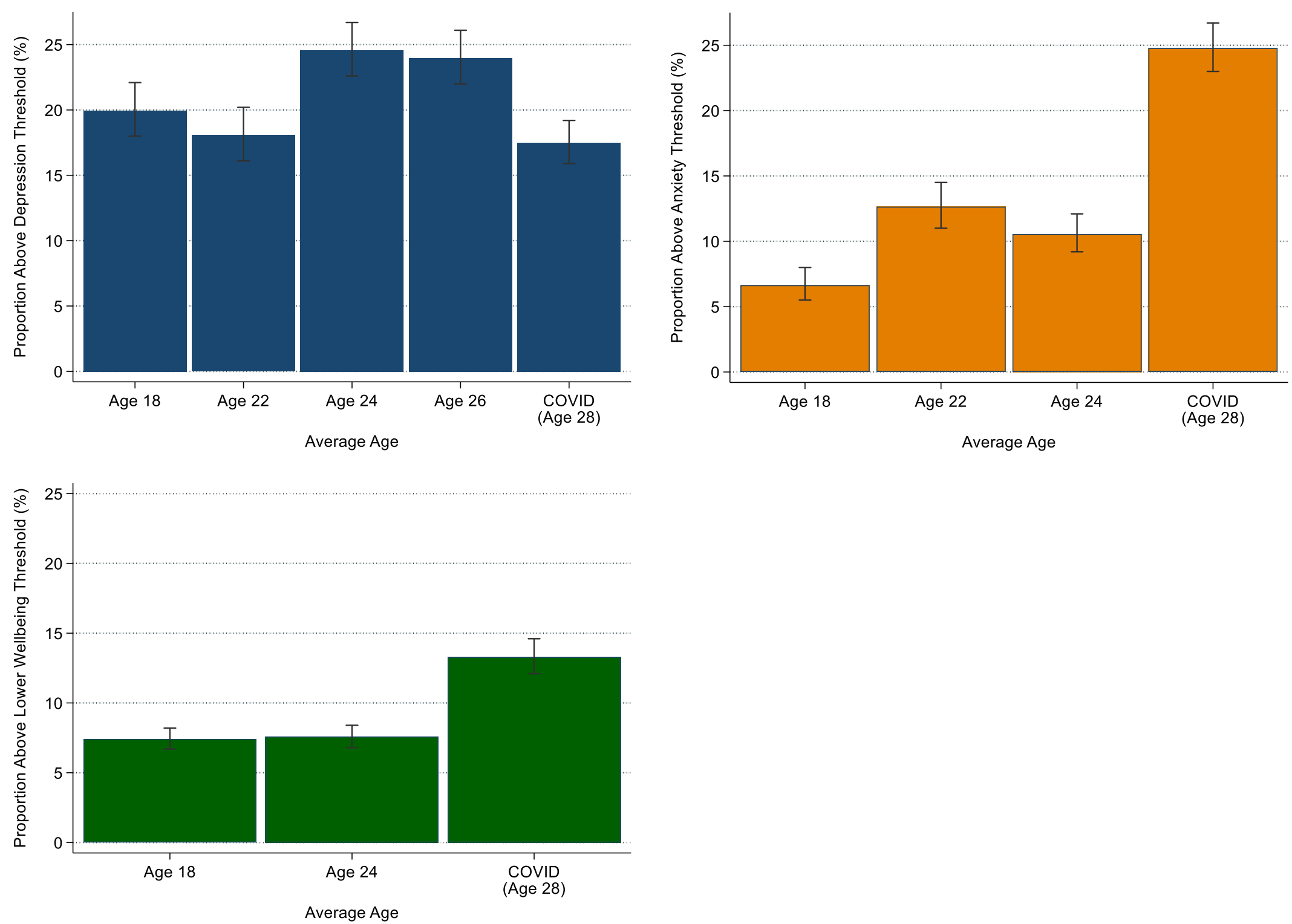

Figure 2. 

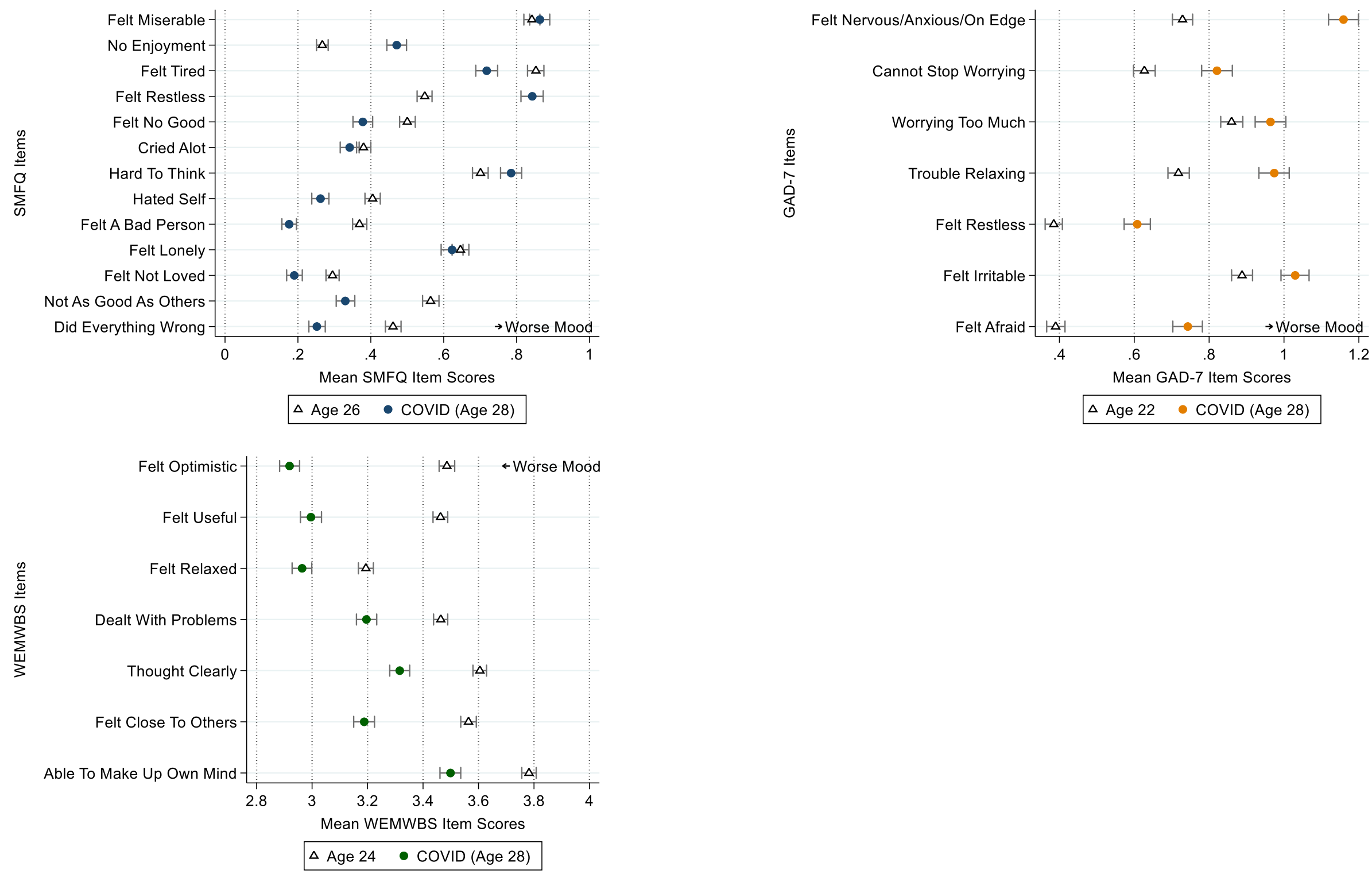

Figure 3. 

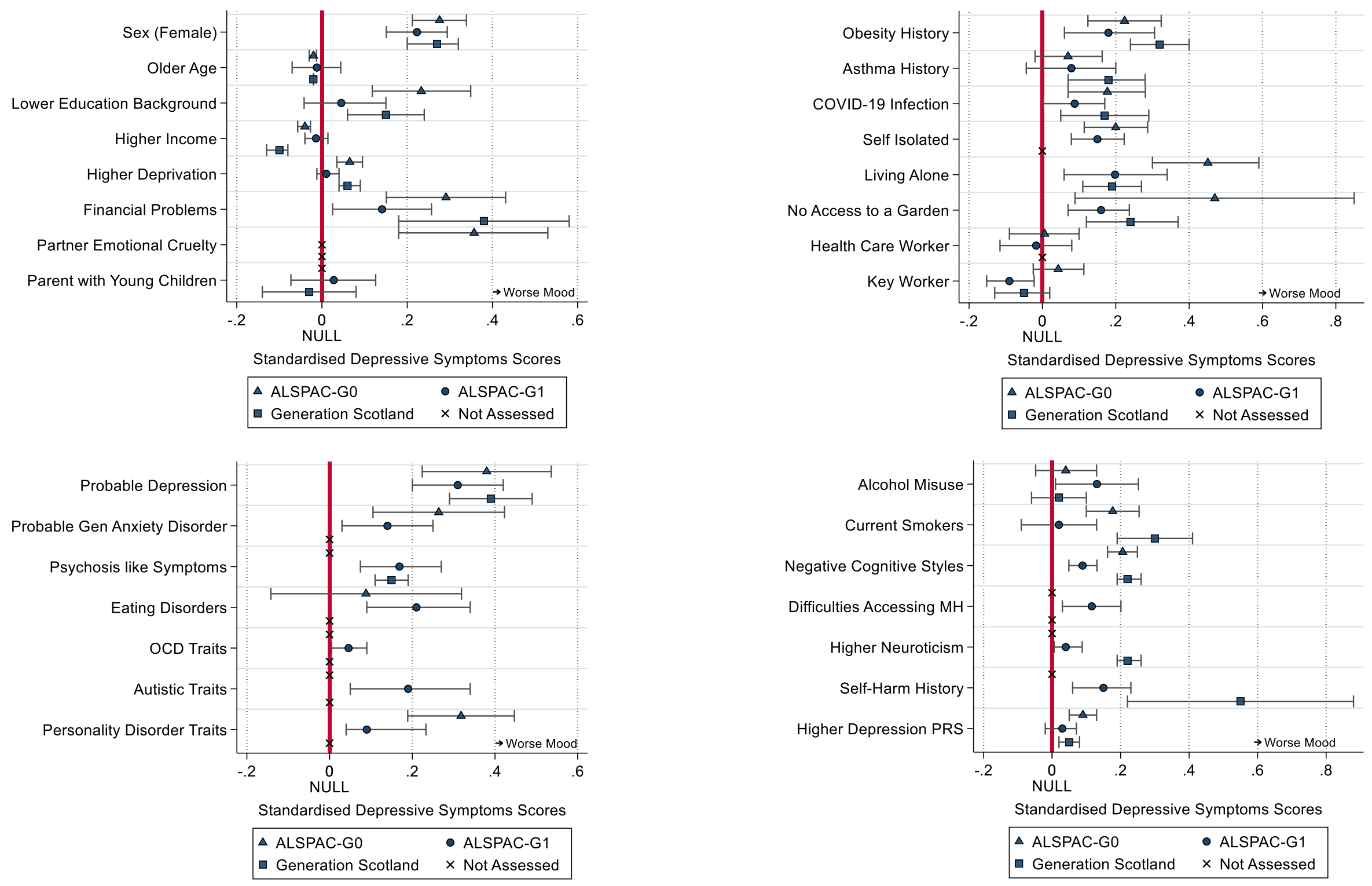

Figure 4. 


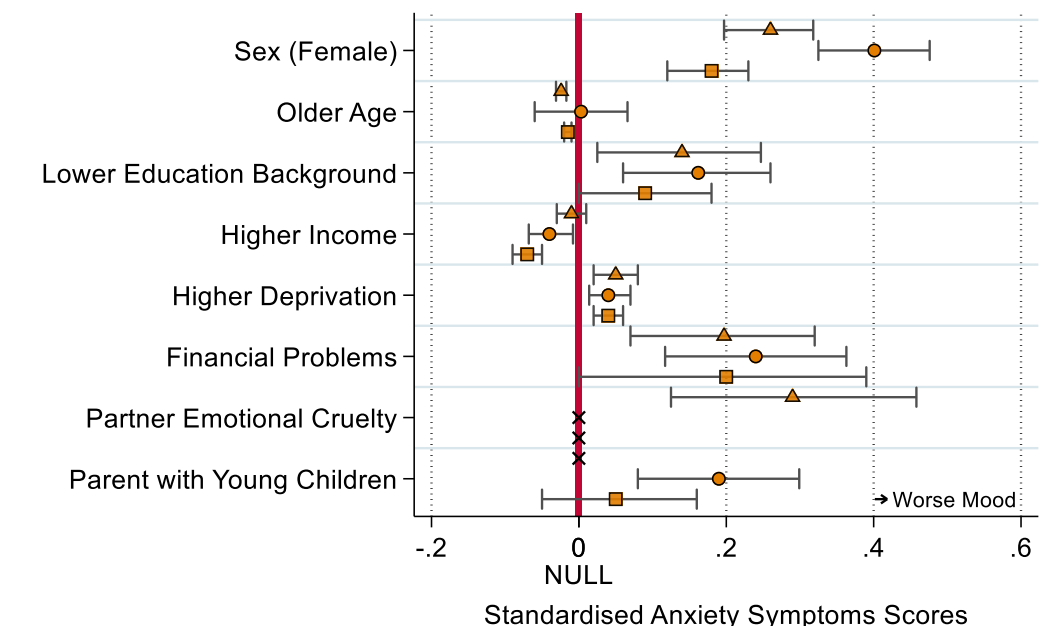

Standardised Anxiety Symptoms Scores

\begin{tabular}{|ll|}
\hline$\triangle$ ALSPAC-G0 & $\circ$ ALSPAC-G1 \\
$\square$ Generation Scotland & $\times$ Not Assessed \\
\hline
\end{tabular}

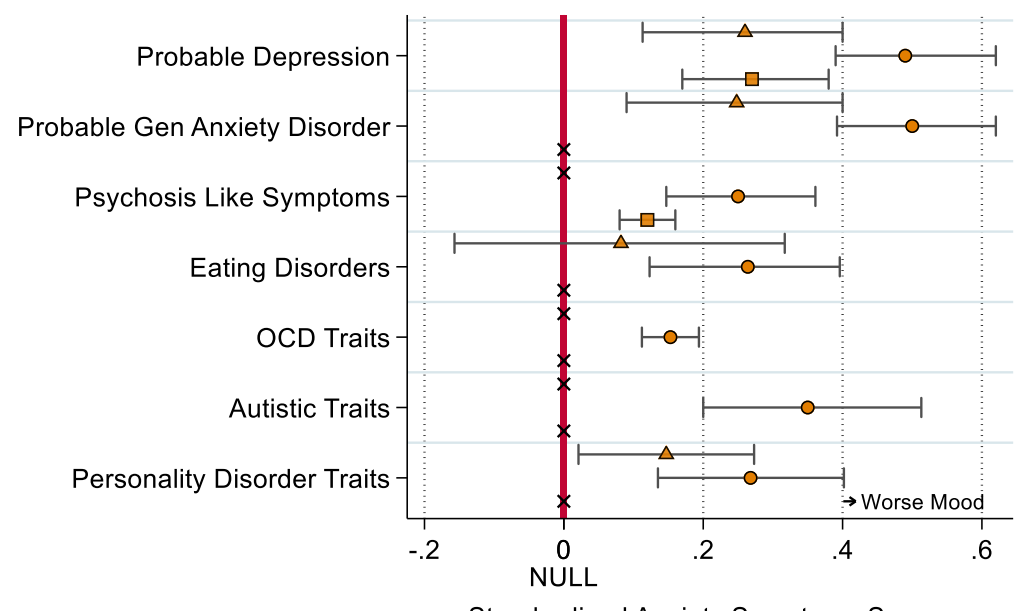

Standardised Anxiety Symptoms Scores

\begin{tabular}{|ll|}
\hline$\triangle$ ALSPAC-G0 & $\circ$ ALSPAC-G1 \\
$\square$ Generation Scotland & $\times$ Not Assessed \\
\hline
\end{tabular}

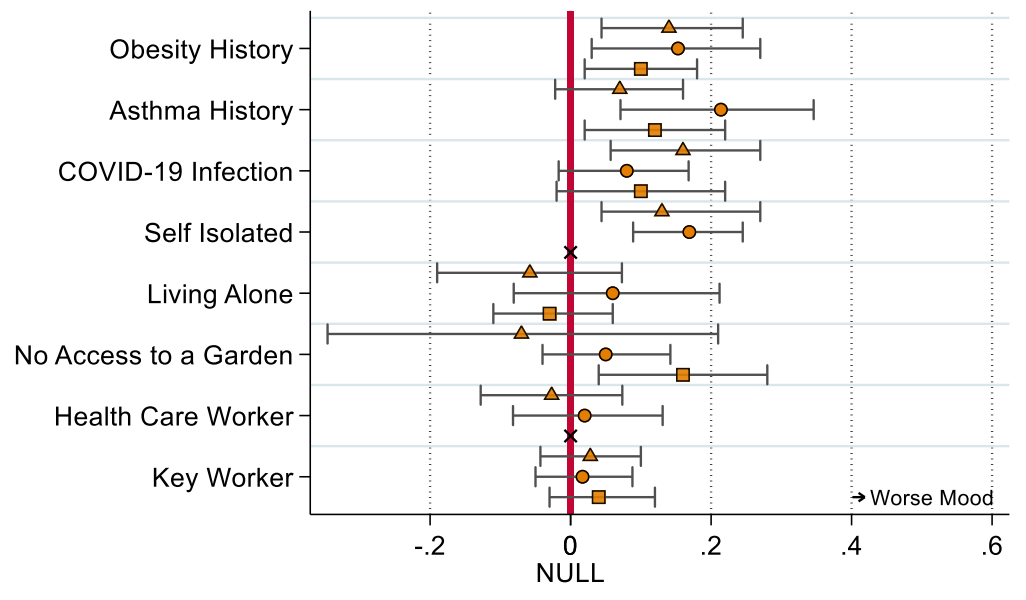

Standardised Anxiety Symptoms Scores

\begin{tabular}{|ll|}
\hline ALSPAC-G0 & $\circ$ ALSPAC-G1 \\
$\square$ Generation Scotland & $\times$ Not Assessed \\
\hline
\end{tabular}

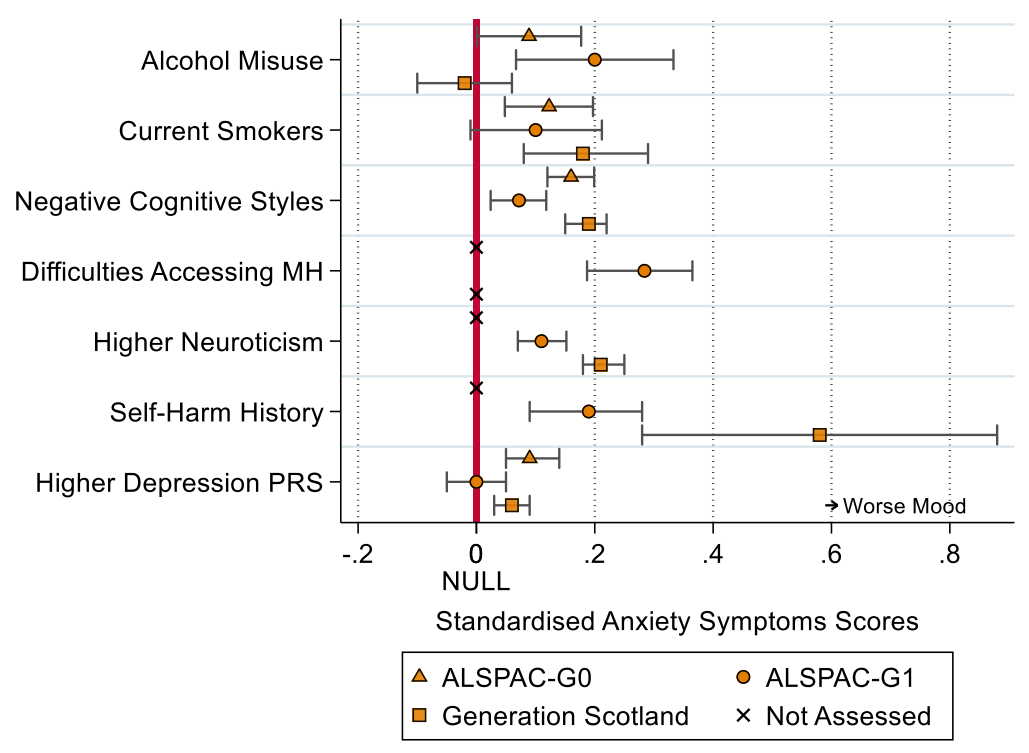

Figure 5. 